\title{
7. The Branding of Traditional Cultural Expressions: To Whose Benefit? ${ }^{1}$
}

\author{
Daphne Zografos Johnsson
}

\section{Introduction}

This chapter is concerned with the legal issues surrounding the branding of traditional cultural expressions (TCEs). Over the past few decades, ethnicity trends combined with today's digital culture have prompted a significant increase in both the commercial and non-commercial branding of TCEs by indigenous communities as well as by third parties. Branding is a process that involves the creation of a unique name and image for a product in the consumers' mind through advertising campaigns or merchandising with a consistent theme. Branding aims to establish a significant and differentiated presence in the marketplace that attracts and retains loyal customers. It is not limited to goods and services, and can also apply to people, places and communities.

Traditional words, images, symbols, music, performances or objects are increasingly being used to brand products, people, communities, corporations and disciplines. Third-party branding practices that use indigenous names, signs and symbols raise issues of ownership, authorisation, attribution and exploitation. On the other hand, some indigenous communities would like themselves to benefit from the branding of their TCEs and to protect their economic interests in indigenous names, signs and symbols. In this perspective, the holders of TCEs are concerned about how best to use intellectual property rights (IPRs) as differentiation tools in the marketplace, prevent misappropriation and misuse, and contribute to the preservation and safeguarding of indigenous names, signs and symbols, and of TCEs generally.

\footnotetext{
1 The views expressed in this chapter are the author's own and do not necessarily reflect the views of the World Intellectual Property Organization or any of its Member States. A version of this paper was delivered at the Trade, Intellectual Property and the Knowledge Assets of Indigenous Peoples: The Development Frontier conference at Victoria University of Wellington, 8-10 December 2010. The trip to New Zealand was funded by the UK Arts \& Humanities Research Council within the context of a project entitled 'Who Owns the Orphans? Traditional and Digital Property in Visual Art'.
} 
This chapter examines how intellectual property (IP) tools can assist indigenous communities in addressing the above issues in relation to the branding of their TCEs.

\section{Third-party Branding}

\section{(a) Ownership and Authorisation}

Some of the questions that may arise in relation to third-party branding of TCEs are: who owns TCEs, who can authorise their branding, and in which situations is such an authorisation required $?^{2}$ Very often, it may not be possible for those wishing to exploit TCEs to identify who to get consent from. This may be the case, for example, in situations where paternity is lost or contested, or where such expressions have been produced within a community, and where it is not possible to identify a specific author or authors, but where the paternity and ownership are vested in the community as a whole. Indeed, the very nature of TCEs is often that they do not have an author, but are attributable to a cultural group or traditional community who are seen as the 'guardians' of the work, and have responsibility for the work, but do not 'own' the work in the Western copyright sense. Having said that, the distinction between individual IPRs and communal traditional knowledge (TK) rights is often an oversimplification, and it should also be kept in mind that there is not one single model of a communal TK rights system. ${ }^{3}$

While it is accepted that many indigenous communities generate and share knowledge from generation to generation collectively, there are also situations in which individual members of these communities can be recognised as creators or inventors distinct from their community. In many cases, contemporary works inspired by traditional styles can and do have an author, and this author can benefit from IP protection such as copyright. Despite that, in some traditional communities the right to create contemporary TCEs and to use pre-existing styles or designs resides with the traditional owners or custodians, who together have the authority to determine whether these TCEs can be used in an artwork and by whom the artwork may be created or exploited. ${ }^{4}$

2 On these questions, see generally, M Torsen and J Anderson, Intellectual Property and the Safeguarding of Traditional Cultures, Legal Issues and Practical Options for Museums, Libraries and Archives (WIPO, Geneva, 2010) <http://www.wipo.int/tk/en/publications/1023.pdf>

3 See C Visser, 'Culture, Traditional Knowledge, and Trademarks: A View from the South', in G B Dinwoodie and M D Janis (eds), Trademark Law and Theory, A Handbook of Contemporary Research (Edward Elgar, 2008) 468; and WIPO, Draft Paper on Customary Law \& the Intellectual Property System in the Protection of Traditional Cultural Expressions and Traditional Knowledge (2006) < http://www.wipo.int/tk/en/consultations/ customary_law/issues.pdf>

4 See, for example, Milpurrurru \& Ors v Indofurn Pty \& Ors (1994-1995) 30 IPR 214: 'The right to create paintings and other artworks depicting creation and dreaming stories, and to use pre-existing designs and 


\section{(b) Attribution}

The holders of TCEs would like the right to be attributed for their TCEs, as well as to be able to object to any false attribution. The latter issue may arise where, for example, imitation products are presented as genuine TCEs in the marketplace. In some industries, it has become common practice to promote nonindigenous products and businesses by using indigenous or traditional names or signs as brand names, trade marks and business names, because consumer belief in authenticity lends tremendous weight and value to cultural objects and handicrafts. ${ }^{5}$ Holders of TCEs are concerned that this practice misleads consumers by falsely suggesting a connection with the community, and leads consumers to believe that the business is owned and run by indigenous people, or that benefits flow back to indigenous or traditional communities.

\section{(c) Exploitation by Third Parties}

Over the past decades, there has been an increasing use, in the course of trade, of indigenous names, signs and symbols by third parties. Well-publicised examples of unauthorised use of such signs can be found in various parts of the world.

In Canada, names of First Nations, such as Algonquin, Mohawk, Haida and Cherokee, as well as symbols such as Indian heads, tepees or tomahawks, are used as trade marks by many non-Aboriginal companies to market products ranging from firearms and axes to tobacco, gasoline and cars. ${ }^{6}$ In the United States, there are many examples of exploitation of Indian names and imagery, notably in relation to college or professional sports teams' names. It is estimated that more than 2,600 high school, college or professional teams have used Native American names and images as mascots, logos and team names. ${ }^{7}$

In New Zealand, there are many examples of unauthorised use of Māori imagery and text by third parties. They include the use of Māori and Polynesian names

well recognised totems of the clan, resides in the traditional owners (or custodians) of the stories or images $[\ldots][w]$ ho together have the authority to determine whether the story and images may be used in an artwork, by whom the artwork may be created, to whom it may be published, and the terms, if any, on which the artwork may be reproduced. [...] If unauthorised reproduction of a story or imagery occurs, under Aboriginal law it is the responsibility of the traditional owners to take action to preserve the dreaming, and to punish those considered responsible for the breach. [...] If permission has been given by the traditional owners to a particular artist to create a picture of the dreaming, and that artwork is later inappropriately used or reproduced by a third party, the artist is held responsible for the breach which has occurred, even if the artist had no control, or knowledge, of what occurred.'

5 See M Asplet and M Cooper, 'Cultural Designs in New Zealand Souvenir Clothing: The Question of Authenticity' (2000) 21(3) Tourism Management 307.

6 See M Cassidy and J Langford, 'Intellectual Property and Aboriginal People: A Working Paper' (Ministry of Indian Affairs and Northern Development, Ottawa, 1999) 22.

7 See K E Behrendt, 'Cancellation of the Washington Redskins' Federal Trademark Registrations: Should Sports Team Names, Mascots and Logos Contain Native American Symbolism?' (2000) 10 Seton Hall Journal of Sport Law 396. 
for a range of toys by Lego; ${ }^{8}$ the use of Māori imagery by Sony Playstation in a game called the Mark of Kri; ${ }^{9}$ the reproduction of various New Zealand icons, such as a hei tiki (greenstone pendant personifying a human ancestor), on paper mats produced by McDonalds and used in their restaurants to cover food trays; ${ }^{10}$ the use of tā moko (Māori facial tattoo) ${ }^{11}$ on the boot of a Ford truck; the use of the words 'MAORI MIX', together with a quasi-Māori design and a map of New Zealand, by tobacco company Philip Morris to market cigarettes in Israel $;^{12}$ and the use of Māori imagery in the fashion industry: $:^{13}$ for example, the use of interlocking curvilinear koru designs on women's swimsuits by New Zealand swimwear manufacturer Moontide in 1998, or Paco Rabanne's Spring 1998 collection featuring two models wearing metal outfits reproducing a stylised moko, to name only a few.

In addition to the commercial exploitation of Māori imagery and text, many personalities have demonstrated a growing fascination with Māori culture. Celebrities such as rock star Robbie Williams and boxer Mike Tyson have exhibited Māori-style tattoos, and soccer player Eric Cantona appeared on the cover of British style magazine GQ with a painted moko on his face. In 1997, the Spice Girls caused offence when they performed a spontaneous haka with fans in Bali. ${ }^{14}$

Finally, a growing number of imitation products, mass-produced outside New Zealand, or by non-Māori artists, can be found on the New Zealand market,

8 In 2001, Danish toy company Lego launched a game called Bionicle, which was challenged by Māori tribes for using Māori and Polynesian names, such as tohunga (a spiritual healer). The storyline of Bionicle is said to be based on stories told by the Rapa Nui people, who live on Easter Island. It features a range of action figures who inhabit an imaginary island called Mata Nui, which has fallen under the control of an evil spirit. The mission of the six heroes, called the Toa (meaning an especially brave Māori warrior), with names such as Whenua (land) or Pohatu (stone), is to liberate the inhabitants of the island. Māori groups approached Lego saying they considered the use of the Māori language by Lego to be inappropriate and offensive. After initially claiming that it hadn't done anything illegal, Lego later admitted it had drawn partly on Polynesian culture for inspiration and had borrowed names from the Māori culture to spice up its toys. The company said that 'future launches of Bionicle sets will not incorporate names from any original culture'. Furthermore, it added that it 'will seek to develop a code of conduct for cultural expressions of traditional knowledge'. See A Osborn, 'Māoris Win Lego Battle', Guardian Unlimited (online), 31 October $2001<$ http://www.guardian. co.uk/world/2001/oct/31/andrewosborn>

9 In March 2003, Sony PlayStation released a game called the Mark of Kri, featuring Rau, a warrior wearing a facial tattoo and carrying a taiaha (an ancient Māori weapon). The game was criticised by Māori IP campaigners for its 'inappropriate and upsetting usage of New Zealand Māori imagery'. In addition, they thought that Rau was promoted as a violent barbarian, thus portraying Māori in a negative manner to the international audience and linking them with stereotyped violence.

10 See S Frankel, 'Third-Party Trade Marks as a Violation of Indigenous Cultural Property' (2005) 8 The Journal of World Intellectual Property 83.

11 Tā moko' is the Māori form of a tattoo tradition which extends throughout the islands of Polynesia.

12 See 'Māori Tobacco Branding Lights up Furore', National Business Review (online) 12 December 2005 $<$ m.nbr.co.nz/article/maori-tobacco-branding-lights-furore-updated $>$

13 See P Shand, 'Scenes from the Colonial Catwalk: Cultural Appropriation, Intellectual Property Rights, and Fashion' (2002) 3 Cultural Analysis 74.

14 See 'Raids on Haka to Continue as Cultures Can't Copyright', Dominion Post (Wellington), 15 July 2006. 
mainly for the tourism industry, to the detriment of local authentic works. It is argued that these products deprive Māori artists of a reliable source of income, and many are considered offensive. Examples of offensive products include tiki pendants made from modern materials such as plastic instead of the traditional pounamu (greenstone), and Matryoshka dolls (Russian-style nesting dolls) featuring a Māori whānau (extended family), that are being sold at tourist gift stores. The dolls were designed by a New Zealand artist and made to order in China. According to Aroha Mead, a senior lecturer in Māori business studies at Victoria University, the dolls are an insult to traditional artists: 'if you compare these to authentic Russian dolls, which are well-designed and beautiful with very intricate patterns, they are cheap and simplistic. They certainly don't have anything to do with Māori culture [...] I don't think any Māori would make something like this. ${ }^{\prime 15}$

The unauthorised exploitation of TCEs by third parties raises a series of questions and concerns. When is borrowing from a traditional culture legitimate, and when is it inappropriate, offensive adaptation or copying? While there is no single set of concerns in relation to third-party branding of TCEs, some common elements can be found. Indigenous communities would like to get protection against the misappropriation and misuse of indigenous names, signs and symbols. They would like to control the ways in which TCEs are used beyond the customary and traditional context, and get equitable sharing of benefits arising from that use. In addition, they would like to prevent the inappropriate and/or offensive use of indigenous names, signs and symbols, and the unauthorised use and commercial exploitation of culturally sensitive names, signs and symbols. Indigenous names, signs and symbols can have a sacred and cultural significance, and using sacred or culturally sensitive names, signs and symbols outside their traditional context, and in ways contrary to customary laws, may cause offence and undermine the social organisation of traditional communities. Also, they would like to preclude the grant, exercise and enforcement of IPRs acquired by unauthorised parties, such as the unauthorised use or the trade mark registration of identical, similar or suggestive signs on imitation products in the marketplace. Finally, they would like to prevent false or misleading indications in trade that suggest endorsement or linkage with a community or tradition-based creations.

Some IP tools can and have been used, with varying levels of success, to address some of these concerns. The next paragraphs focus on the use of trade mark law. The trade mark law system can provide protection against offensive and deceptive uses of indigenous names, signs and symbols, and has the ability to prevent third parties from using the signs.

15 See C Simcox, 'Māori Russian Dolls Made in China, Sold in NZ', Dominion Post (online), 11 April 2008 $<$ http://www.stuff.co.nz/dominion-post/361204> 


\section{Trade Mark Protection Against Offensive and Deceptive Use}

To be registered as a trade mark, a sign must satisfy the criteria of registrability which are laid down by the law. Some signs may be subject to absolute bars to registration and therefore be inherently unregistrable. These absolute bars exclude from registration signs that are contrary to public order or morality and may therefore be considered offensive to sections of the community, such as indigenous groups, and signs that are deceptive.

\section{(a) Offensive Marks}

The concepts of 'contrary to morality' or 'contrary to public order' are very broad, and require a value judgement to be made by trade mark registries. Offence may relate to words and/or images, and to matters of race, sex, religious beliefs, general matters of taste and decency, or, in our case, cultural offence. There are examples in various jurisdictions of stakeholders attempting to use absolute grounds to prevent the registration of trade marks containing offensive imagery and text. In New Zealand, the Trade Marks Act was amended in 2002 to take into account cultural offensiveness during the trade mark registration process. Under the New Zealand Trade Marks Act 2002, a trade mark application can be denied on grounds of cultural offence to significant sections of the community, and in particular to Māori. ${ }^{16}$ In addition, the Act provides for the creation of an advisory committee to help the Commissioner of Trade Marks assess the potential offensiveness of trade marks. In the United States, a trade mark may be refused registration if it consists of matter that may disparage, or falsely suggest a connection with, persons, living or dead, beliefs, or national symbols, or bring them into contempt or disrepute. ${ }^{17}$

\section{(b) Deceptive Marks}

If the trade mark applied for seems to suggest that the good or service has an indigenous origin, where such origin would be a significant factor for the average consumer, and this is not actually the case, the trade mark must be objected. The prohibition will apply to marks which, though distinctive, contain some

\footnotetext{
16 New Zealand Trade Marks Act 2002, s 17(1)(c)(i). See Intellectual Property of New Zealand (IPONZ), Practice Guidelines 16 - Māori Advisory Committee \& Māori Trade Marks (2012) <http://www.iponz.govt.nz/ $\mathrm{cms} /$ trade-marks/practice-guidelines-index/practice-guidelines/16-maori-advisory-committee-maori-trademarks>

17 Lanham Act 1946, 15 USC 1052, s 2(a).
} 
kind of suggestion or allusion that is inaccurate. The risk of deception must, however, be a real one, and fanciful trade marks will be accepted even though they might be deceptive.

It should be noted that trade mark law will not prevent the offensive or deceptive use of indigenous names, signs and symbols where the user does not seek to register a trade mark, ${ }^{18}$ nor will it prevent the registration of indigenous names, signs and symbols by third parties where the signs are not considered offensive or deceptive.

\section{Trade Mark Registration to Prevent Others from Using the Sign}

Holders of TCEs may also register indigenous names, signs or symbols to remove them from the field of trade and business, and prevent them from being used by third parties.

In Canada, the First Nations peoples have registered a series of petroglyphs (ancient rock painting images) as 'official marks' ${ }^{19}$ to prevent their improper use by third parties. They wanted to protect the petroglyphs from unauthorised reproduction and commodification on commercial items such as T-shirts, jewellery and postcards. The petroglyphs have special religious significance to the members of the First Nation Snuneymuxw people, who considered such uses offensive. Once the petroglyphs were registered as official marks, the Snuneymuxw were able to ask local shops to cease selling items that reproduced the registered images without permission. Members of the Snuneymuxw First Nation subsequently indicated that local merchants and commercial artisans did stop using the petroglyph images, and that the trade mark registration, accompanied by an education campaign to make others aware of the significance of the petroglyphs to the Snuneymuxw First Nation, had been very successful. ${ }^{20}$

\footnotetext{
18 In situations where the a third party does not seek to register a trade mark, it may be possible to use unfair competition laws or passing off to prevent competitors from misrepresenting their goods as to the source or quality, i.e. to prevent them from suggesting that they originate from a community or are authentic/ genuine goods.

19 'Official marks' are special types of marks under section 9 of the Canadian Trade-Marks Act which prohibit the adoption, in connection with a business, of any badge, crest, emblem or mark which has been adopted or used by a public authority. In turn, a 'public authority' is defined as any entity which operates under a significant degree of government control and whose activities benefit the public as opposed to profiting private interests. Aboriginal groups and native organisations which meet these criteria are eligible to qualify as public authorities.

20 See WIPO IGC Secretariat, Report on the Review of Exisiting Intellectual Property Protection of Traditional Knowledge, WIPO Doc WIPO/GRTKF/IC/4/7 (2002), annex II, 1.
} 
It should be noted that the defensive use of trade marks may require an amendment to the trade mark legislation of countries in which the commercial use of trade marks is mandatory. Furthermore, in some countries, national legislation requires that only legitimate businesses may file for trade mark registration. Such a requirement would also impose an amendment.

The trade mark system does not offer a comprehensive system of protection, as it would be prohibitively expensive to register all names, signs and symbols associated with a community's TK and TCEs. It would also be unreasonable and unrealistic to consider, or to aim for, a blanket prohibition on the use of all words and imagery with an indigenous connotation.

\section{Branding by the Holders of TCEs}

Brands are multi-faceted tools that can also be used to the advantage of the holders of TCEs for the purpose of identification, authentication, protection and commercial exploitation of their own products. In particular, where issues of livelihood, reward and profitability are prominent motivators for the creation of cultural expressions, the use of marketing strategies and IPRs can be very valuable.

The recipe for a successful business is one that uses quality products, a distinctive brand and an effective marketing strategy. The essence of branding lies in its capacity to foster the sales of a product by creating an emotional link with its consumers. This should in turn be combined with an effective marketing strategy that will create demand for the product. These key elements are often coupled with other important factors, such as raw materials, financial capital, good distribution networks and special skills. ${ }^{21}$

From an IP perspective, successful branding can involve the use of legal tools such as trade marks, certification and collective marks, and geographical indications (GIs), each operating according to their own sets of rules and pursuing related yet distinct objectives of protection. The following paragraphs will examine each of these IPRs in turn.

\section{(a) Trade Marks}

Trade marks are signs which distinguish goods or services of one undertaking from those of other undertakings, ${ }^{22}$ and convey information about the source

21 See ITC and WIPO, 'Marketing Crafts and Visual Arts: The Role of Intellectual Property. A Practical Guide' (ITC and WIPO, Geneva, 2003) 13.

22 TRIPS Agreement, art 15(1). 
or trade origin of the goods or services in respect of which they are used. In addition to their distinguishing function, trade marks have an advertising function. They play a pivotal role in a company's branding and marketing strategies, contributing to the definition of the image and reputation of the company's products in the eyes of consumers. The image and reputation of a company create trust, which is the basis for establishing a loyal clientele and enhancing a company's goodwill. Finally, they provide information about, amongst other things, the quality of the goods and services. Consumers need this information to make informed purchasing decisions. Trade marks provide an incentive for companies to invest in maintaining or improving the quality of their products to ensure that products bearing their trade mark have a positive reputation. Consumers who are satisfied with a product are likely to buy or use that product again.

The trade mark system can help indigenous communities benefit from the branding of their TCEs, and protect their economic interests in those TCEs by allowing the registration of distinctive indigenous names, signs or symbols. Trade mark registration, combined with an appropriate marketing strategy, can enable indigenous communities to differentiate their products, and build a brand image and reputation. This can increase consumer recognition of TCEs and the commercial benefits for holders of TCEs, as the addition of a trade mark on a good increases its value. However, it should be noted that there are costs associated with the registration of a trade mark: for example, in relation to the registration and renewal fees, the enforcement of rights and the implementation of a marketing strategy.

\section{(b) Geographical Indications}

'Geographical indications' (GIs), as defined in Article 22(1) of the Agreement on Trade-Related Aspects of Intellectual Property Rights (TRIPS Agreement) are indications $s^{23}$ which identify a $\operatorname{good}^{24}$ as originating ${ }^{25}$ in the territory of a 
member, or a region or locality in that territory, where a given quality, reputation or other characteristic ${ }^{26}$ of the good is essentially attributable to its geographical origin. ${ }^{27}$ In other words, under the TRIPS definition, GIs communicate important information on: (a) the name of the product; (b) the area of geographical origin of the product; and (c) its given quality, reputation or other characteristics which are essentially attributable to that geographical origin.

Article 22(2) of the TRIPS Agreement establishes the general standard of protection that must be available for all GIs. It provides that 'legal means' must be provided to interested parties to prevent the use of GIs which mislead the public as to the geographical origin of the goods. It also requires that legal means be provided to prevent use which constitutes an 'act of unfair competition' within the meaning of Article 10 bis of the Paris Convention. However, while it is mandatory for member states to provide protection to GIs, they are free to determine the appropriate method of protection when implementing the provisions of the Agreement within their own legal system and practice. ${ }^{28}$ Over the past decade, a variety of different legal concepts have been used to protect GIs at the national and regional levels. They include, in particular, laws of unfair competition and passing off, protected appellations of origin and registered GIs, collective and certification marks, and administrative schemes of protection. ${ }^{29}$ The choice of a protection mechanism or a combination of systems of protection will usually depend on the legal tradition and historical and economic conditions of the jurisdiction concerned. However, the differences between these systems will have a bearing on important questions, such as conditions of protection, entitlement to use and scope of protection.

26 Under TRIPS, 'quality, reputation or other characteristics' of a good can each be a sufficient basis for eligibility as a GI, where they are 'essentially attributable' to the geographical origin of the good in question. The word 'attributable' seems to suggest an objective criterion. However, while this might be possible for a quality or characteristic, reputation suggests a subjective element. Indeed, the reference to quality refers to physical characteristics of the good. On the other hand, the reference to reputation makes clear that the identification of a particular objective attribute of the good is not a prerequisite to conferring protection. It is enough that the public associates a good with a territory because the public believes the good to have desirable characteristics. Indeed, GIs, like trade marks, may be built up through investment in advertising. The drawback is that the public may be deceived as to the quality of goods and their territorial link through false or misleading advertisement. See UNCTAD-ICTSD, above n 23, 290.

27 The words 'essentially attributable' to the geographical territory are intended to establish the link between the product and the relevant territory. While a literal reading of 'territory' would suggest that the link must be physical: that is, that the product must embody certain characteristics because of the soil conditions, weather or other physical elements in a place, the terms 'reputation' and 'essentially attributable' allow flexibility. Therefore, 'essentially attributable' can be understood also to refer to human labour in the place or to goodwill created by advertisement in respect to the place. See UNCTAD-ICTSD, above n 23, 290291. This also seems to be confirmed by the drafting history of TRIPS. In the 1990 draft (Draft of 23 July 1990 (W/76), para 2), the quality, reputation or other characteristic of the product had to be attributable to its geographical origin, including natural and human factors. The qualification 'natural and human factors' did not, however, reappear in the final text of TRIPS, which uses the broader term of 'geographical origin'. See D Gervais, The TRIPS Agreement, Drafting History and Analysis (2nd ed, Sweet \& Maxwell, 2003) 188-189.

28 TRIPS Agreement, art 1(1).

29 See UNCTAD-ICTSD, above n 23, 291. 
GIs have traditionally been associated with agricultural products, foodstuffs, wines and spirits. However, in recent years GIs have been said to be potentially useful in protecting indigenous knowledge. At the fifth session of the World Intellectual Property Organization (WIPO) Intergovernmental Committee on Intellectual Property and Genetic Resources, Traditional Knowledge and Folklore (IGC), it was pointed out that some TCEs, such as handicrafts made using natural resources, may qualify as 'goods' which could be protected by GIs. ${ }^{30}$

TCEs can be tangible expressions in which culture is manifested or expressed, such as productions of art or handicrafts. They include, in particular, drawings, designs, paintings, carvings, sculptures, pottery, terracotta, mosaic, woodwork, metalware, jewellery, baskets, needlework, textiles, glassware, carpets, costumes and musical instruments.

These tangible expressions or 'handicrafts' may qualify as goods which could be protected by GIs if they present the necessary qualities for GI protection. ${ }^{31}$ Such qualities would usually include a symbolic association between the handicraft or artisanal product and a particular culture which acknowledges the influence of tradition in its creation. Furthermore, these handicrafts would be produced either completely by hand or with the help of hand-tools or mechanical means, as long as the direct manual contribution of the craftsperson remains the most substantial component of the finished products. They would be produced using raw materials from sustainable resources, and their distinctive features could be utilitarian, aesthetic, artistic, creative, culturally attached, decorative, functional or traditional, or have a religious or social symbolism. Finally, the creative activity would occur within a small group or a community-based environment. ${ }^{32}$

A number of common features can be identified between, on the one hand, GIs and the goods they relate to and, on the other, TCEs. They are (a) the communal element: while GIs identify a good that is produced by a number of different producers, TCEs are usually produced within a community; (b) the element of tradition: while GIs are often based on traditional formulae and processes, TCEs are produced according to traditional methods; (c) the element of time: the

\footnotetext{
30 See WIPO IGC Secretariat, Consolidated Analysis of the Legal Protection of Traditional Cultural Expressions, WIPO Doc WIPO/GRTKF/IC/5/3 (2003) 52.

31 On GIs and TK/TCEs, see generally M Blakeney, 'Protection of Traditional Knowledge by Geographical Indications' in C Antons (ed), Traditional Knowledge, Traditional Cultural Expressions and Intellectual Property Law in the Asia-Pacific Region (Kluwer Law International, 2009) 87.

32 See UNESCO/ITC, 'International Symposium on Crafts and the International Market: Trade and Customs Codification' (Final Report, Manila, 1997) 6; K Basu, 'Marketing Developing Society Crafts: A Framework for Analysis and Change' in J A Costa and G J Bamossy (eds), Marketing in a Multicultural World: Ethnicity, Nationalism and Cultural Identity (Sage Publications, 1995) 261, D S Gangjee, Geographical Indications Protection for Handicrafts under TRIPS (MPhil Thesis, University of Oxford, 2002) $5<$ http://users.ox.ac. uk/ edip/gangjee.pdf>
} 
know-how attached to both GIs and TCEs is transmitted from one generation to the other; (d) the geographical link: while GIs are granted for products which have a relationship with the land, local resources or the environment, TCEs are generally linked to a specific place where a certain product is made, or to traditional methods or conditions used in a specific place for making a product, often using raw material from sustainable resources. In addition, while the value of a GI is linked to its origin, the value of TCEs is linked to the knowledge that a particular community from a particular region has produced it.

The GI system is therefore consistent with the nature of indigenous knowledge in that GIs work as a collective right and provide protection that is potentially unlimited in time, as long as the distinctive link between the goods and the place is maintained and the indication has not fallen into genericity.

There are many examples around the world of indigenous names, signs and symbols that have been registered as GIs. These include TALAVERA DE PUEBLA pottery and OLINALÁ handicrafts from Mexico; JABLONEC jewellery, glass and crystal from the Czech Republic; MADEIRA embroidery from Portugal; GORODETS paintings, ROSTOV enamel and KARGOPOL clay toys in the Russian Federation; and Mysore silk, Kashmir Pashmina and Pochampally Ikat in India. ${ }^{33}$

While GIs do not directly protect the actual knowledge associated with TCEs, which remains in the public domain and is open to misappropriation, they can indirectly contribute to their protection in several ways. First, GIs protect the reputation or goodwill accumulated over time, and can safeguard a niche market segment. They can provide protection to TCEs against misleading and deceptive trading practices, and prevent third parties from using a protected GI on goods that do not originate from a given region and/or do not possess the requisite quality or characteristics. Secondly, GIs enable product differentiation. Where a product is successfully differentiated through the use of a GI, the market is segmented, and access to a specific market segment can be restricted to producers of products possessing the necessary quality, reputation or other characteristics, and who are carrying on their activity in the relevant geographical area. Thirdly, the registration of a GI can create value for the holders of TCEs and enhance the development of rural communities. ${ }^{34}$ For example, the registration of a GI has been shown to increase production output and land value, and the certainty afforded by legal protection can create opportunities for investment in a product and region. Fourthly, the registration of indigenous names, signs

33 On Indian GIs, see K Das, 'Prospects and Challenges of Geographical Indications in India' (2010) 13 Journal of World Intellectual Property 148.

34 See T W Dagne, 'Harnessing the Development Potential of Geographical Indications for Traditional Knowledge-Based Agricultural Products' (2010) 5 Journal of Intellectual Property Law \& Practice 441; D Zografos, 'Geographical Indications \& Socio-Economic Development' (I Qsensato Working Paper 3) <http:// www.iqsensato.org/pdf/iqsensato-wp-3-zografos-dec-2008.pdf> 
or symbols as GIs can help indigenous groups gain recognition for the cultural significance of their TCEs and preserve them for future generations. Finally, GIs provide information and educate consumers about the origin, quality and characteristics of the goods.

\section{(c) Certification and Collective Marks}

Certification and collective marks are special types of marks. They inform the public about certain characteristics of the products or services marketed under the mark. Article 7 bis of the Paris Convention provides for the mutual obligation of registration and protection of collective marks in the countries of the Union. ${ }^{35}$ However, it leaves each country be the judge of the particular conditions under which a collective mark shall be protected, and provides that it may refuse protection if the mark is contrary to the public interest. Even though the Paris Convention refers only to collective marks, it is generally understood that the term also includes certification marks. ${ }^{36}$ Certification and collective marks can be indications of geographical origin. As such, they can be protected under the TRIPS Agreement. The TRIPS Agreement incorporates by reference a number of articles of the Paris Convention, including Article 7 bis. As a consequence, collective marks which belong to associations and are serving as GIs are protected under TRIPS. ${ }^{37}$

A certification mark is a mark which indicates that the goods or services in connection with which it is used are certified by the proprietor of the mark in respect of geographical origin, material, mode of manufacture of goods or performance of services, quality, accuracy, or other characteristics. In other words, it is an indication of the conformity of goods or services to particular standards, stipulated by the proprietor of the mark.

35 As originally established in Paris in 1883, the Paris Convention made no provision for the protection of collective marks. However, at the Washington Conference of 1911, Article 7bis was introduced in the Convention. It was later amended at the London Conference of 1934. Article 7bis of the Paris Convention provides that:

The countries of the Union undertake to accept for filing and to protect collective marks belonging to associations the existence of which is not contrary to the law of the country of origin, even if such associations do not possess an industrial or commercial establishment.

Each country shall be the judge of the particular conditions under which a collective mark shall be protected and may refuse protection if the mark is contrary to the public interest.

Nevertheless, the protection of these marks shall not be refused to any association the existence of which is not contrary to the law of the country of origin, on the ground that such association is not established in the country where protection is sought or is not constituted according to the law of the latter country.

36 See N Dawson, Certification Trade Marks, Law and Practice (Intellectual Property Publishing Limited, 1988) 13.

37 See J Belson, Certification Marks (Sweet \& Maxwell, 2002) 23. For a discussion of the protection of TCEs with geographical indications, see ch 6 . 
Any person or entity that authorises traders to use a certification in relation to certain products or services may apply for a certification mark. However, the applicant must be considered competent to certify the products concerned. The owner of the certification mark is ultimately responsible for controlling its use and for ensuring that the mark is not used on non-compliant goods. The applicant must also supply a copy of the regulations governing the use of the certification mark, which must indicate who is authorised to use the mark, the characteristics to be certified by the mark, how the certifying body is to test those characteristics and supervise the use of the mark, the fees to be paid in connection with the administration of the certification scheme, and the procedures for resolving disputes. Unlike collective marks, certification marks are not confined to any membership. They can be used by anybody who complies with the standards defined by the owner of the certification mark.

A collective mark is a mark which distinguishes the goods or services of members of an association which is the proprietor of the mark from those of other undertakings, without any requirement for certification of the goods or services. In most jurisdictions, applicants are required to supply a copy of the regulations governing the use of the collective mark. These generally indicate who is authorised to use the mark, the conditions of membership of the association, any conditions for use of the mark, as well as sanctions against misuse. The cost, duration and scope of protection applicable to collective marks are similar to those of ordinary trade marks. However, since the cost of registering a collective mark is divided among the members of the association, it becomes much cheaper for an individual member. This can be an attractive argument for indigenous and local communities for whom the cost of registering an ordinary trade mark to market their products or services could be dissuasive.

An association of indigenous producers or craftspeople can register a collective mark and authorise its members to use it in relation to their products or services. In that way, a collective mark can be used as a tool to help them obtain consumer recognition and customer loyalty, and develop a joint marketing campaign for their products. Collective marks are often used to show membership of a union, association or other organisation. Membership as such may be an incentive to some customers to buy a product bearing the collective mark. In addition, a collective mark can have the function of informing the public about certain features of a product associated with it. Unlike certification marks, the proprietor association of a collective mark does not have to set standards to be met before 
its members can use the mark. However, it may do so if it wishes. Consequently, collective marks may also perform a certification function. ${ }^{38}$ This is particularly relevant in countries that do not provide for registration of certification marks. ${ }^{39}$

There are various examples, in a number of jurisdictions, of use of certification and collective marks to protect and promote TCEs. These have had varying levels of success. They include the toi iho ${ }^{\mathrm{tm}}$ certification mark in New Zealand, ${ }^{40}$ the Alaska Silver Hand Program in Canada, ${ }^{41}$ and the Marca Colectiva FIEB ${ }^{42}$ and the Auténtico Pemon ${ }^{43}$ certification marks in Venezuela, to name only a few.

\section{Certification and collective marks can be valuable tools for the protection and promotion of TCEs. They allow for collective use and can denote common}

38 Note that there is a certain level of confusion between certification and collective marks. As Jeffrey Belson pointed out, during the first century of the registration system there was confusion over the respective roles of certification and collective marks, and this situation has not improved due to a proliferation and growing divergence of policy and law on certification and collective marks. For example, a mark may become a Community Trade Mark collective mark and a national domestically registered certification mark. Also, because there can be varying degrees of conflation, the usefulness and specificity of the information conveyed by a collective mark may at times be close to that of a traditional certification mark and at other times less so. See Belson, above n 37, 42-43.

39 As regards certification and collective marks, national laws for the registration of trade marks can be classified into three categories: (a) those which permit registration of certification marks only, in which case use of the marks is open to all who meet the standards; (b) those which permit registration of collective marks only, in which case collective marks may also perform a certification function. However, because they are registered as collective marks, their use is permitted only to members of the proprietor association, and (c) those which permit registration of both certification and collective marks. In this category also, collective marks may perform a certification function. See Dawson, above $\mathrm{n} 36$.

40 Toi ihoTM is a registered certification trade mark used to promote and sell authentic, quality Māori arts and crafts, and to authenticate exhibitions and performances of Māori arts and artists. It is intended to certify that the arts and crafts are made by a person of Māori descent and to provide a mark of quality. It was developed and implemented in response to calls from Māori to assist them retain ownership and control of their taonga (treasures) and maintain the integrity of their art culture. While, overall, the introduction of the toi ihoTM mark has been beneficial to artists and consumers alike, the certification mark was disinvested in 2010. Some of the reasons for the disinvestment were that: (a) toi ihoTM no longer fitted in the strategic priorities of Creative New Zealand; (b) there was insufficient funding and resources to run the scheme appropriately; (c) the breadth of the scheme's design was too wide. Despite the disinvestment, artists have not been deregistered and the toi ihoTM scheme is currently in a transition phase. One possible plan for its future would be for a group of Māori artists to create a trust to take over the toi ihoTM mark. See Creative New Zealand, Statement on toi ihoTM (2009) <http://www.creativenz.govt.nz/en/news/creative-new-zealand-statement-on-toi-iho>

41 The Alaska Silver Hand Program is a certification mark that certifies the authenticity of Alaska Native art and guarantees consumers that items bearing the Silver Hand identification seal were handcrafted in Alaska by an Alaska Eskimo, Aleut, or Indian craftsperson or artist, and made wholly or in significant part of natural materials. See Alaska State Council on the Arts, Silver Hand Program and Permit Application <http://www. eed.state.ak.us/aksca/Forms/individuals/SH.pdf>

42 The Marca Colectiva FIEB (Federation de Indigenas de Estado Bolivar) distinguishes goods and services manufactured or offered by indigenous people, associations or production centres affiliated to the Indigenous Federation of the Bolivar State. It demonstrates the material and spiritual bond between the goods and services manufactured or offered by the Bolivar State indigenous people, and the habitat and cultural background in which they have lived from ancestral times. See Grupo de Investigación sobre, 'Politicas Públicas de Propriedad Intelectual' (Universidad de Los Andes, Mérida, Venezuela) < http://www.cjp.ula.ve/ gpi/documentos/fieb_content_defl.pdf>

43 The Auténtico Pemon certification mark certifies and promotes indigenous handicrafts, indigenous artisans and the Pemon culture more generally. It includes the Autentico Pemon certification mark, collaboration mark and certified merchandiser mark. See ibid. 
indigenous origin. They do not confer a monopoly right, but they limit the class of people who can use a certain name, sign or symbol. The cost of registering and renewing a collective mark is divided among the members of the association and is consequently much cheaper than registering an ordinary trade mark. Similarly, marketing costs can also be shared by the members of the association. Finally, they provide protection that is potentially unlimited in time, provided the necessary steps are taken for their renewal.

The registration of a certification or collective mark can help indigenous communities distinguish their TCEs, promote their art and artists nationally and internationally, and maintain the integrity of their culture. In addition, a certification or collective mark can be a valuable tool to help improve their economic position and ensure they get fair and equitable returns. Finally, these tools can be used by indigenous communities to raise public awareness and maximise consumer certainty as to the authenticity of the goods marketed under the mark.

Having said that, the effectiveness of a certification scheme depends on the way it is set up, implemented and policed. A successful certification scheme needs to gain the support of the stakeholders - that is, the indigenous communities and the owner of the mark will need to engage in public education campaigns for the acceptance of the mark, so that the public, the relevant industry bodies and consumers become familiar with the characteristics that the certification scheme guarantees. Finally, where the certification or collective mark is also a quality mark, there needs to be an oversight of quality of the goods or services for which accreditation is sought.

\section{Concluding Comments}

The laws of trade marks, certification and collective marks, and GIs have not been designed, for the most part, with the protection of indigenous interests as an underlying policy goal. The utility of these laws as tools for holders of TCEs to protect their indigenous names, signs and symbols is therefore often coincidental. ${ }^{44}$ Although these legal tools may help them achieve some of their objectives, they will usually not provide a comprehensive system of protection. For example, as was highlighted above, even if the registration of a trade mark may prevent the registration of offensive and deceptive marks, it will not prevent the offensive and deceptive use of indigenous names, signs and symbols where the user does not seek to register a trade mark, and nor will it prevent

44 See S Frankel, ‘Trademarks and Traditional Knowledge and Cultural Intellectual Property' in Graeme B Dinwoodie and Mark D Janis (eds), Trademark Law and Theory, A Handbook of Contemporary Research (Edward Elgar, 2008) 437. 
the registration of indigenous names, signs and symbols by third parties where the signs are not considered offensive or deceptive. In the same way, the use of a certification mark or authenticity label will not, in itself, prevent the sale of imitation products in the marketplace. Further, when dealing with the protection and branding of TCEs, a distinction must be drawn between the protection of the actual knowledge and the protection of the indigenous names, signs and symbols associated with the TCEs. The systems of protection discussed above may protect the indigenous names, signs and symbols associated with the knowledge, but the actual knowledge is not protected, remains in the public domain and is open to misappropriation by third parties.

Holders of TCEs should carefully plan how they will identify, protect and manage their IP assets. IP and marketing go hand in hand, so the use of IPRs to identify, authenticate, protect and exploit TCEs should form part of a planned and systematic marketing strategy. Similarly, IP assets are a basic requirement for a successful marketing strategy, as they can send messages about the product and help differentiate it from other products. 